\section{Differential expression of neurofilament triplet proteins in brain development}

\section{Gerry Shaw \& Klaus Weber}

Max Planck Institute for Biophysical Chemistry, D-3400 Goettingen, FRG

Axonal transport studies and biochemical fractionation have led to the concept that the three 'triplet' proteins [approximate molecular weights 200,000 (200K), 145,000 (145K) and $68,000(68 K)]$ are the essential components of mammalian neurofilaments ${ }^{1-5}$. Using a correlated biochemical and immunological approach, we have now shown that the $200 \mathrm{~K}$ protein is under separate developmental control during rat brain differentiation and that the time of its expression differs in different regions. We were unable to detect $200 \mathrm{~K}$ protein by immunofiuorescence or in total brain filament preparations from prenatal rat brain, although the $145 \mathrm{~K}$ and $68 \mathrm{~K}$ proteins are both present in an apparently identical distribution. During development, progressively more $145 \mathrm{~K}$ - and $68 \mathrm{~K}$-positive neurofilamentous bundles can be stained with $200 \mathrm{~K}$ antibodies, paralleling the increasing quantities of this protein detected biochemically in brain filament preparations. We conclude that $200 \mathrm{~K}$ protein probably has a more specialized role in neurofilament architecture and function than the other two triplet proteins.

Preparations of total intermediate filaments were obtained from rat brains of various ages by a modification of the method of Dahl et al. ${ }^{6}$ and analysed by SDS-polyacrylamide gel electrophoresis (see Fig. 1). The $200 \mathrm{~K}$ protein was scarcely detectable on Coomassie blue-stained gels until 5 days after birth, and was still very much attenuated by day 13 after birth in relation to the quantity found in the adult. The $68 \mathrm{~K}$ and $145 \mathrm{~K}$ proteins were present at all stages examined. We obtained further evidence for the later appearance of significant quantities of the $200 \mathrm{~K}$ protein using immune blots of whole brain proteins from animals of various ages (Fig. 2). A similar result can be seen in previously published gels of filament preparations from brain ${ }^{6}$ and optic nerve ${ }^{7}$ of newborn rats, though in neither case did the authors comment on it.

We were also able to document further the differential triplet protein expression during rat brain development by doublelabel immunofluorescence microscopy using antibodies raised in rabbit and guinea pig, each of which was specific for only one of the three triplet proteins ${ }^{8}$. We also used a recently described mouse monoclonal antibody specific for the $200 \mathrm{~K}$ protein $^{9}$. We found that this antibody performed comparably with our rabbit and guinea pig polyclonal $200 \mathrm{~K}$ protein antisera.

Frozen sections of 5-day prenatal brain revealed numerous profiles which could be stained equivalently with $68 \mathrm{~K}$ and $145 \mathrm{~K}$ antibodies (Fig. $3 a, b$ ). As in adult brain ${ }^{10}$, we were unable to detect any processes that could be stained only with $145 \mathrm{~K}$ or $68 \mathrm{~K}$ antibodies alone. This result was observed in all specimens at all later developmental stages examined, and we conclude that the $68 \mathrm{~K}$ and $145 \mathrm{~K}$ proteins are invariably closely associated in each neurofilamentous bundle during the developmental sequence studied. We were unable to stain any region of the 5 -day prenatal brain with any of the $200 \mathrm{~K}$ antibodies (Fig. $3 c$, d). For most regions of the 1-day postnatal brain also, $200 \mathrm{~K}$ antibody failed to stain $145 \mathrm{~K}$ - and $68 \mathrm{~K}$-positive profiles, though some thicker processes in the brain stem were $200 \mathrm{~K}$ positive (Fig. $4 a, b)$. Neither at this stage nor later were we able to detect processes positive for $200 \mathrm{~K}$ which were not positive, in double-label immunofluorescence, for the $68 \mathrm{~K}$ and the $145 \mathrm{~K}$ proteins. We examined several regions of the peripheral nervous system of 1-day postnatal animals and found that most
Fig. 1 Polyacrylamide gel electrophoresis of intermediate filament preparations from brains of variously aged animals. Lane 1,1 day prenatal; 2,1 day postnatal; 3,5 days postnatal; 4,7 days postnatal; 5,13 days postnatal; 6 , adult (about 3 months postnatal). 200,145 and 68 indicate the position of the triplet proteins; $\mathrm{V}$, the position of vimentin. The gel was loaded so that approximately equivalent quantities of $68 \mathrm{~K}$ protein were applied. In the original gel, the $200 \mathrm{~K}$ protein was not detectable in lanes 1 and 2 , first became visible in

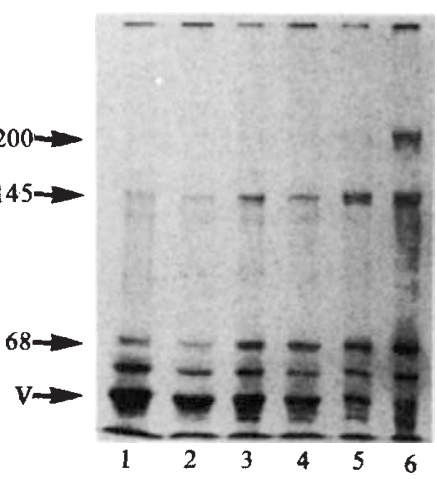
lane 3 , corresponding to 5 days postnatum. In lanes 4 and 5 , slightly more $200 \mathrm{~K}$ protein was present. Even in lane 5, however, corresponding to 13 days postnatum, the relative amount of $200 \mathrm{~K}$ protein is much lower than that found in the adult (lane 6). Preparations were derived from the entire brain, including cerebellum and brain stem. About $1.5 \mathrm{~g}$ of starting material was Dounce homogenized in 20 vols of Dahl buffer ${ }^{6}$ (phosphate-buffered saline plus $1 \%$ Triton $\mathrm{X}-100,0.6 \mathrm{M} \mathrm{KCl}, 10 \mathrm{mM} \mathrm{MgCl}, 2 \mathrm{mM}$ EGTA $1 \mathrm{mM}$ EDTA, $0.5 \mathrm{mg} \mathrm{ml}^{-1}$ tosyl-1 -arginine-methylester- $\mathrm{HCl}, 0.15 \mathrm{mM}$ phenylmethylsulphonyl fluoride, $\mathrm{pH}$ 7.1). After centrifugation for $10 \mathrm{~min}$ at 12,000 r.p.m. at $4{ }^{\circ} \mathrm{C}$ in an SS34 Sorvall rotor, the supernatant $\left(\mathrm{S}_{1}\right)$ was saved and the pellet was again homogenized with the same volume of Dahl's medium. After a further centrifugation, the supernatant $\left(S_{2}\right)$ was again saved. The pellet was resuspended in $8 \mathrm{ml}$ of Dahl's medium, and sonicated using a Sonifier B12 (Branson Sonic Power Company, Dahlburg, USA) at a setting of $3 \mathrm{~W}$ for $10 \mathrm{~s}$. The material was spun in the Sorvall centrifuge as before. The supernatant was saved $\left(S_{3}\right)$ and the pellet was again resuspended in $8 \mathrm{ml}$ of Dahl's medium and sonicated for $10 \mathrm{~s}$ at 4 W. The supernatant $\left(\mathrm{S}_{4}\right)$ was collected after a further centrifugation. All supernatants were then centrifuged in the Beckman Type $40 \mathrm{~T} 1$ rotor at $4{ }^{\circ} \mathrm{C}$ for $30 \mathrm{~min}$ at 35,000 r.p.m. The pellets produced were dissolved in sample buffer and analysed on $6 \%$ analytical SDS-polyacrylamide gels. The highest yield of the neurofilament triplet proteins was found in the $S_{3}$ fractions, and these were accordingly compared. The relative quantities of the three triplet proteins detected in the other fractions of a particular preparation were similar to those found in the $S_{3}$ fraction. This gel also documents the relative decrease in vimentin expression during development. In the conditions used here, for reasons unknown, glial-fibrillary acidic protein does not co-purify with vimentin and neurofilaments, but is found predominantly in the final pellet fraction. We could, however, see a progressively relative increase in expression of this protein during development. Both findings are in agreement with previously published reports (see, for example, refs 6,7 ).

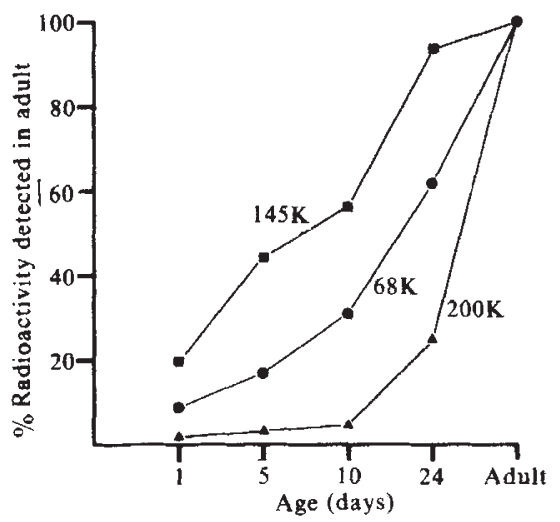

Fig. 2 Immune blotting of whole brain proteins from animals of different ages with neurofilament antibodies. Brains were homogenized in Dahl's buffer $^{6}$ as described previously and quickly boiled in SDS sample buffer. Protein concentration was estimated using the method of Lowry et al. ${ }^{18}$ and equal quantities of total protein were applied to $6 \%$ SDS-polyacrylamide gels. Proteins were transferred to nitrocellulose sheets by the method of Towbin et al. ${ }^{19}$. The nitrocellulose sheets were stained with rabbit and guinea pig antisera strongly positive for each of the three triplet proteins ${ }^{8}$. Antibody staining was visualized using ${ }^{125}$ I-labelled protein $\mathrm{A}$ followed by autoradiography. We quantified our results in the following manner: using heavily overexposed autoradiographs and suitable masks, we could locate the position of the radioactive protein A-antibody complex corresponding to a particular transferred triplet protein on each nitrocellulose sheet. These regions, each one corresponding to the transferred protein from a differentage brain preparation, were carefully excised and the contained radioactivity estimated using a Beckman Gamma 300 counter. We used three different triplet protein antibodies from rabbit and a further three from guinea pig and obtained consistent results with different antibodies to the same triplet protein. The average resuits are plotted as a percentage of the radioactivity found in the adult preparations. The $200 \mathrm{~K}$ protein clearly becomes a major component much later than the other two proteins. 
nerve fibres positive for $145 \mathrm{~K}$ and $68 \mathrm{~K}$ protein were also positive for $200 \mathrm{~K}$ protein (Fig. $3 e, f$ ).

Sections of most regions of the 5-day and 13-day postnatal brain showed increasing numbers of $200 \mathrm{~K}$-positive processes (Fig. $4 c, d$ ). However, even at these stages, few 68K- and $145 \mathrm{~K}$-positive fibres in the cerebral cortex were stained with $200 \mathrm{~K}$ antibodies. We have previously reported that most, but not all, neurofilamentous bundles in the adult brain could be strongly stained with $200 \mathrm{~K}$ protein antibodies (ref. 10 and Fig. $4 e, f)$. However in the cerebral cortex, among other regions, some fibres positive for $68 \mathrm{~K}$ and $145 \mathrm{~K}$ antibodies were not strongly stained by $200 \mathrm{~K}$ antibodies. We concluded that certain neurofilaments in the adult brain probably did not contain $200 \mathrm{~K}$ protein, but did contain $145 \mathrm{~K}$ and $68 \mathrm{~K}$ protein. This conclusion is now supported by the immunological and biochemical evidence reported here for the existence of such neurofilaments in the developing brain. The combined results strongly indicate that the $200 \mathrm{~K}$ protein is under separate developmental control from the $145 \mathrm{~K}$ and $68 \mathrm{~K}$ proteins, and that it appears later in

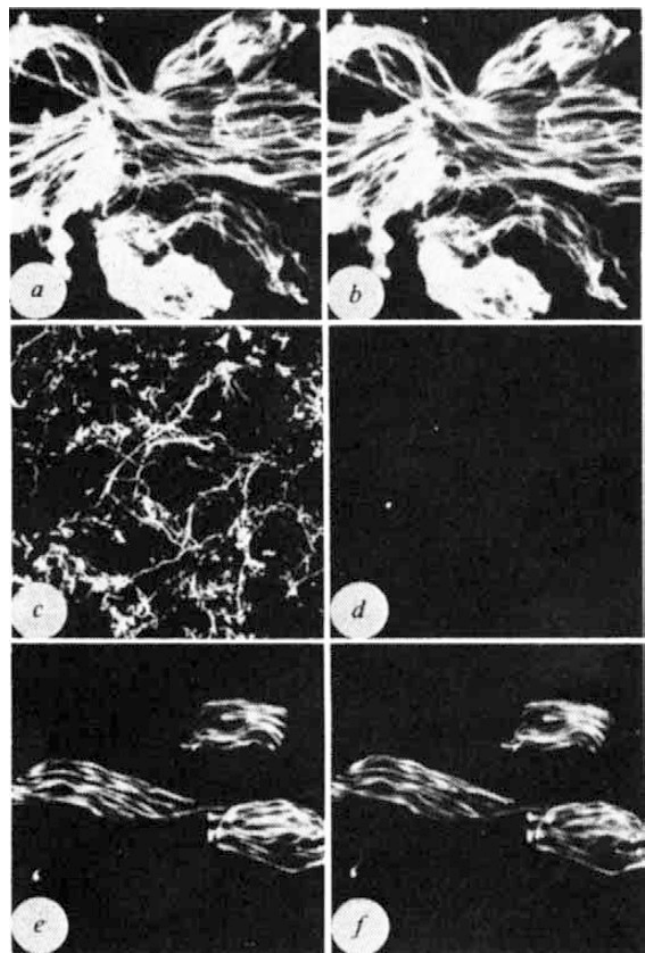

Fig. 3 Double-label immunofluorescence microscopy with individual triplet protein-specific antibodies on the developing nervous system. $a, b$, Corresponding fluorescein $(a)$ and rhodamine $(b)$ views of a section of a 5-day prenatal brain. $a$ Was stained with rabbit $68 \mathrm{~K}$ neurofilament antibody $b$ with guinea pig $145 \mathrm{~K}$ neurofilament antibody. The two antigens appear to have an identical distribution at this resolution. $\times 950, c, d$ Fluorescein c) and rhodamine (d) views of a section from a 1-day postnatal cerebral cortex. $c$ Was stained with rabbit $68 \mathrm{~K}$ antibody, $d$, with $200 \mathrm{~K}$ monoclonal mouse antibody ${ }^{9}$ (compare with Fig. $4 e, f$ ) $.68 \mathrm{~K}$ antibody stains strongly, but no staining can be detected with the $200 \mathrm{~K}$ antibody $\times 600$. Corresponding fluorescein $(e)$ and rhodamine $(f)$ views of nerve fibre bundles in the 1 -day postnatal rat tongue. $\times 380$. $e$ Was stained with rabbit $200 \mathrm{~K}$ antibody, $f$, with guinea pig $68 \mathrm{~K}$ antibody. The distribution appears identical here, though some profiles (not shown) did not exhibit $200 \mathrm{~K}$ staining. As with the central nervous system, all $68 \mathrm{~K}$-positive processes could also be stained with $145 \mathrm{~K}$ antibodies and vice versa. All double-label immunofluorescence experiments were performed essentially as described previously ${ }^{10}$. We used the monoclonal antibody in double-label immunofluorescence using fluoresceinated or rhodaminated goat antimouse second antibody. Fluoresceinated goat anti-mouse was used when the monoclonal antibody was used in conjunction with a guinea pig polyclonal antibody, which was labelled with rhodaminated goat anti-guinea pig. Rhodaminated goat anti-mouse was used when the monoclonal was tested against antibodies raised in rabbit, which were labelled with fluoresceinated goat anti-rabbit antibody. Control experiments, as described previously ${ }^{8.10}$, indicated no significant leakage between fluorescein and rhodamine channels in these experiments. Fluorochrome-coupled second antibodies were routinely used at dilutions of 1:20 and were purchased from Capell Laboratories with the exception of goat anti-rabbit fluorescein (Miles-Yeda).

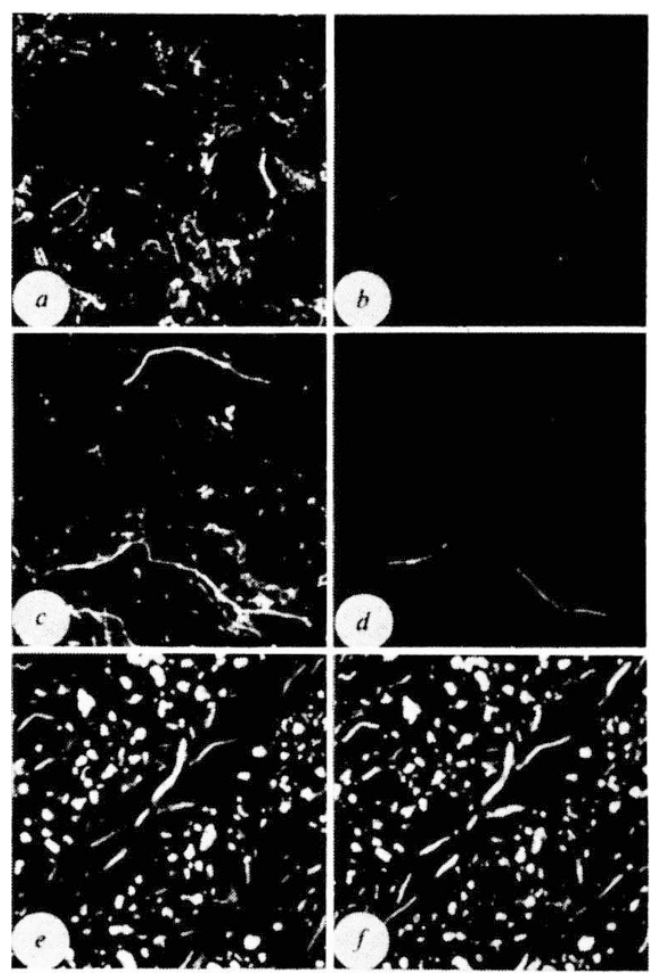

Fig. 4 Double-label immunofluorescence with triplet protein antibodies illustrating the progressive appearance of the $200 \mathrm{~K}$ protein during development. $a$, Fluorescein and $b$, rhodamine views of double-labelled sections of 1 -day postnatal rat brain stem. a Was stained with rabbit $68 \mathrm{~K}$ protein antibody, $b$, with guinea pig $200 \mathrm{~K}$ protein antibody. Some neurofilamentous profiles can be stained with both antibodies, but most are only stainable with $68 \mathrm{~K}$ antibody, $\times 600$. $c$, Fluorescein fluorescence and $d$, rhodamine fluorescence of a brain stem region of a 5-day postnatal animal. $c$ Was stained with rabbit $68 \mathrm{~K}$ antibody, $d$, with mouse $200 \mathrm{~K}$ monoclonal antibody. As with $a$ and $b$, fibres stainable with $200 \mathrm{~K}$ and $68 \mathrm{~K}$ antibody are visible, though most profiles are only visible in the $68 \mathrm{~K}$ protein channel. $\times 600$. $e$, $f$, Fluorescein $(e)$ and rhodamine $(f)$ views of a section of aduit cerebellar white matter. $e$ Was stained with rabbit $68 \mathrm{~K}$ protein antibody, $f$, with mouse $200 \mathrm{~K}$ monoclonal antibody. As reported previously, there is no detectable difference in the distribution of the triplet proteins in this region of the brain. $\times 600$.

development than the latter two neurofilament components. Furthermore, $200 \mathrm{~K}$ is expressed in some processes before it occurs in others and ultimately becomes a component of most but probably not all neurofilamentous profiles.

In our earlier study ${ }^{10}$, we were able to identify some of the $200 \mathrm{~K}$-negative neurofilamentous profiles in the adult cerebral hemisphere as the dendrites of pyramidal cells. All profiles that could clearly be identified as axonal stained strongly for all three neurofilament antigens. The possibility that the $200 \mathrm{~K}$ protein is a marker of mature axons, and may not be found in dendrites, would be consistent with the localization of $200 \mathrm{~K}$ protein in the adult, and with the early appearance of this protein in the peripheral nervous system and brain stem. The studies of axonal transport on adult animals which originally led to the triplet hypothesis ${ }^{1}$ and later similar studies (for example refs 2,11 ) all reflect the transport of exclusively axonal neurofilaments. All published biochemical preparations of neurofilaments use adult tissue and probably select strongly for axonal neurofilaments ${ }^{3,5,12-16}$. It therefore seems possible that the existence of neurofilaments composed only of the $68 \mathrm{~K}$ and $145 \mathrm{~K}$ proteins, perhaps dendritic in origin, has been hitherto masked by the selection for and the predominance of neurofilaments containing all three proteins. Future immunoelectron microscope studies may allow a direct evaluation of this possibility.

The results reported here raise the question of the function of $200 \mathrm{~K}$ protein in neurofilament architecture. Our previous immunoelectron microscope study ${ }^{17}$ and that of Willard and Simon ${ }^{5}$ both make use of neurofilaments containing $200 \mathrm{~K}$ protein. Both studies suggest that the $200 \mathrm{~K}$ protein, when present, 
shows a peripheral disposition and may protrude from the surface, possibly interacting with other cellular components or with neighbouring neurofilaments. The results presented here indicate that the function performed by the $200 \mathrm{~K}$ protein is not rigidly required by every neurofilament, and is not needed at all stages of development. It should be possible to correlate the presence and absence of this protein with morphological and physiological attributes of particular neurones, and so elucidate the role of this protein in neuronal dynamics.

We thank E. Debus for providing monoclonal antibody to the $200 \mathrm{~K}$ neurofilament protein. G. S. was supported by a postdoctoral fellowship from the Max Planck Society.

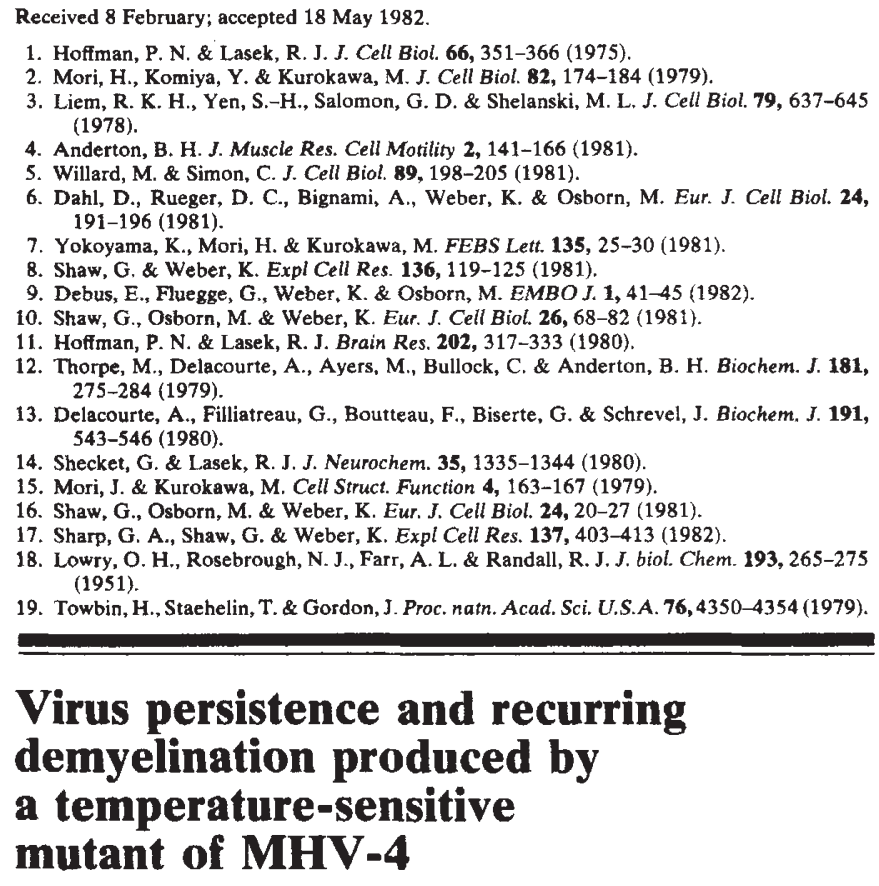

\section{Virus persistence and recurring demyelination produced by a temperature-sensitive mutant of MHV-4}

\author{
Robert L. Knobler*†, Peter W. Lampert $\dagger$ \\ \& Michael B. A. Oldstone* \\ * Department of Immunopathology, Scripps Clinic and Research \\ Foundation, La Jolla, California 92037, USA \\ † Department of Pathology, UCSD School of Medicine, La Jolla, \\ California 92093, USA
}

Mouse hepatitis virus type 4 (MHV-4, the JHM strain), a positive-strand RNA virus of the coronavirus family, is well documented as an inducer of acute ${ }^{1-4}$ and chronic ${ }^{5,6}$ demyelination in mice, as well as subacute demyelination in rats ${ }^{7,8}$, due to a cytolytic infection of oligodendrocytes ${ }^{3,4,7}$. However, experiments to explore the role of virus and host factors in the production of chronic or recurrent demyelinating disease have been limited because MHV-4 usually produces demyelination in conditions that frequently induce a fatal necrotizing encephalomyelitis ${ }^{1-9}$. To circumvent this problem, we had made and selected mutant viruses that caused both a high incidence of demyelination and a low incidence of encephalitis-induced mortality ${ }^{9}$. One such mutant, designated ts8, consistently caused acute demyelinating disease in over $90 \%$ of intracerebrally or intranasally (natural route of infection) inoculated, 4-5 weekold mice from several susceptible strains within 6-10 days ${ }^{9,10}$. In addition, ts8 typically did not cause fatal necrotizing encephalitis, showing a low mortality $(<5 \%)^{9,10}$. This reflected a unique tropism of ts8 for oligodendrocytes, but a limited one for neuronal cells ${ }^{11}$. We now report that ts8 is also useful for inducing persistent infection of the mouse central nervous system (CNS). The histopathological correlate of this infection is chronic recurrent demyelination, and virus can be demonstrated ultrastructurally in intact oligodendrocytes, in the vicinity of demyelinated areas.
$\mathrm{BALB} / \mathrm{c}$ mice, 4-5 weeks old, were inoculated intracerebrally with $10^{4}$ plaque-forming units (PFU) of ts 8 . Tissue homogenates from one group of mice were prepared for virus titration as $10 \% \mathrm{w} / \mathrm{v}$ suspensions ${ }^{12}$. An identically treated group was killed at various time points by intracardiac perfusion with a paraformaldehyde-glutaraldehyde fixative ${ }^{11}$. CNS tissue was embedded in Epon, and sections were stained with uranyl acetate and viewed with a Zeiss EM10 electron microscope ${ }^{11}$. Figure 1 shows the amounts of virus found in brains of animals (five each) at 2, 4, 7, 10, 28, 60 and 365 days after inoculation. Although virus titres had declined by the seventh day after inoculation, brains from three of five mice studied at 365 days after inoculation still yielded infectious virus. Corresponding results were recorded for spinal cord tissues. All animals (25 mice) examined histopathologically 7 days after infection and later, had some degree of demyelination. Virus isolated from animals killed $1 \mathrm{yr}$ after inoculation retained the temperaturesensitive growth characteristics of the initial inoculum. For example, assay of one such sample yielded $1 \times 10^{4} \mathrm{PFU}$ per $\mathrm{g}$ brain at $34^{\circ} \mathrm{C}, 6 \times 10^{3} \mathrm{PFU}$ per $\mathrm{g}$ at $37^{\circ} \mathrm{C}$ and $<10 \mathrm{PFU}$ per $\mathrm{g}$ brain at $39.5^{\circ} \mathrm{C}$. This sample is representative of all three isolates.

The maximal degree of acute demyelination usually corresponded directly to the amounts of infectious virus carried and

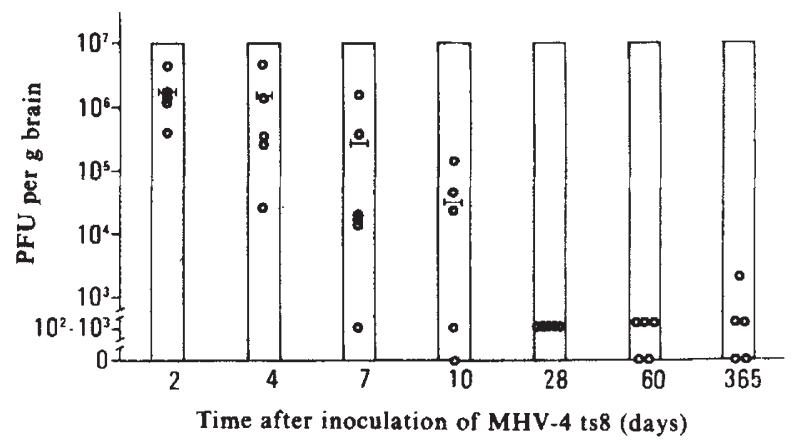

Fig. 1 Virus titres following intracerebral inoculation of $10^{4} \mathrm{PFU}$ MHV -4 ts 8 on day 0 , are expressed as PFU per $g$ of brain tissue. Less than $10 \mathrm{PFU}$ per $\mathrm{g}$ is indicated as zero. Brain homogenates were prepared as a $10 \%$ suspension $(w / v)$ from each animal killed $^{12}$. Five animals were assayed at each time point at $37^{\circ} \mathrm{C}$ and the bar indicates the mean virus titre. A decline in virus titre became evident 7 days after infection and reached a plateau, evident 28 days and thereafter. Virus was isolated from only three

of five animals at both 60 days and 365 days after infection.

was associated with infiltrating inflammatory cells. Remyelination, characterized by thin myelin sheaths around large axonal profiles, was evident at 28 days post-infection (Fig. 2a). Thereafter, recurrent demyelination in areas that had undergone remyelination was found at 57 days (Fig. $2 b$ ) and later. The chronic demyelinating lesion was not usually associated with perivascular cellular infiltrates, although acute demyelination was associated with infiltrating inflammatory cells.

Recurrent demyelination, usually occurring in small foci, was evident at 365 days (Fig. $2 c, d$ ). Virions could be demonstrated ultrastructurally in the cytoplasm of oligodendrocytes located near sites of demyelination $1 \mathrm{yr}$ after inoculation (Fig. $2 e$; this photomicrograph is characteristic of coronavirus virions found in the cytoplasm of several different oligodendrocytes).

Thus, this MHV-4 mutant establishes a reproducible persistent infection in mice and induces a progression from acute demyelinating disease, to a chronic recurring form. The reproducibility of this model now allows a detailed study of virus, host and genetic factors affecting virus persistence and replication in oligodendrocytes, remyelination and recurrent demyelination. 